\title{
PUBLICIDADE E TRANSPARÊNCIA NA JURISDIÇÃO CONSTITUCIONAL
}

\section{PUBLICITY AND TRANSPARENCY IN THE CONSTITUTIONAL JURISDICTION}

Thiago Sacchetto ${ }^{1}$

Resumo: A inovação levada a cabo pelo Supremo Tribunal Federal brasileiro de permitir que os meios de comunicação de massa transmitam ao vivo e integralmente parcela de suas sessões de julgamento tem dividido opiniões no que concerne à virtuosidade ou ao desvalor da prática, não havendo, até então, um mínimo de consenso teórico sobre a sua conveniência. Em razão das características jurídicas e dos efeitos normativos advindos de certos acórdãos proferidos pelas cortes constitucionais na fiscalização constitucional de atos normativos, entende-se que a instauração de regimes de ampla publicidade e transparência trata-se, genuinamente, de um verdadeiro dever elementar dos Estados Democráticos no transcorrer do século XXI.

Palavras-chave: Jurisdição constitucional. Deveres estatais. Publicidade e transparência. Direito de acesso à informação.

\begin{abstract}
The innovation carried out by the Brazilian Federal Supreme Court to allow the mass media to transmit live and integrally part of their judging sessions has divided opinions regarding virtuosity or the devaluation of the practice in a way that does not exist until then a minimum of theoretical consensus on its suitability. Due to the legal characteristics and the normative effects of certain judgments given by the constitutional courts in the judicial review of normative acts, it is understood that the establishment of widely publicized and transparent regimes is genuinely a real elementary duty of States in the 21st century.
\end{abstract}

Keywords: Constitutional jurisdiction. State duties. Publicity and transparency. Right of access to information.

\footnotetext{
Mestre em Ciências Jurídico-Políticas pela Faculdade de Direito da Universidade de Lisboa; Especialista em Advocacia Pública pelo Instituto para o desenvolvimento democrático; doutorando em Direito Político pela Universidade Federal de Minas Gerais; Professor no Centro Universitário UNA; Avenida Governador Valadares, 640, Centro, 32510-010, Betim, Minas Gerais, Brasil; tcsacchetto@gmail.com
} 


\section{Introdução}

Justiça constitucional é um tema deveras abrangente. Consagrados juristas, em diversos países, escreveram vasta bibliografia sobre a matéria, tanto em perspectivas teoréticas quanto em perspectivas pragmáticas (FERNÁNDEZ RODRIGUEZ, 2002; TAVARES, 2005; MORAIS, 2006; NOVAIS, 2012; URBANO, 2014; MENDES, 2014), em enfoque de direito nacional como em abordagens comparativas (CAPPELLETTI, 1968; FROMONT, 1996; GARCIA BELAUNDE; FERNÁNDES SEGADO, 1997; PERGORARO, 1998), a tratar desde suas questões mais genéricas, até os seus aspectos mais particulares (FAVOREU, 1992; LUTHER; ROMBOLI; TARCHI, 2000).

Curiosamente, a despeito de existir significativa fartura bibliográfica sobre a temática, muito pouco se escreveu, e se tem escrito, a respeito do regime de publicidade e de transparência das sessões de julgamento realizadas pelas cortes constitucionais (PASQUINO, 2015; WEST, 2012; NEUBERGER, 2011). Genericamente, a doutrina tem se concentrado em analisar os aspectos processuais dos modelos colegiados de deliberação (EDWARD, 1995, p. 555-558; CELOTTO, 2004, p. 48-56; ANCEL, 2005; FERNÁNDEZ SEGADO, 2009; PERI, 2012, p. 19 e ss.) de modo que as questões atinentes ao direito fundamental de acesso às informações produzidas por esses órgãos têm sido timidamente enfrentadas.

Embora assaz relevante para a Teoria da Constituição, o tema não tem sido abordado pela literatura nacional com considerável préstimo e dedicação dogmática, havendo, sobretudo, a tergiversação de questões pontuais sobre o regime publicístico adotado pelo Supremo Tribunal Federal (MEDINA, 2014; BINENBOJM, 2009; SILVA; MENDES, 2009), não obstante recentes trabalhos indicarem a assunção de um novo marco teórico para as pesquisas sobre a matéria no País (FONTE, 2016; ABDO, 2011).

Mundo afora, diversos sistemas subsistem no que concerne ao grau de abertura dos procedimentos instrutórios e deliberativos por meio dos quais, eventualmente, atos normativos são afastados pelos órgãos de cúpula da Justiça constitucional (RAFFAELLI, 2012). Seria possível concluir que alguns desses sistemas de publicidade são mais republicanos que outros em consonância com as diretrizes paradigmáticas do Estado Democrático de Direito e em conformidade com a origem popular do Poder Soberano?

\section{Os deveres de publicidade e de transparência para as atividades estatais}

Além de estar ontologicamente estruturado em um modelo de organização jurídico-política que reconhece a dignidade da pessoa humana, institui a legitimidade do poder em alicerces 
democráticos e estabelece direitos fundamentais (NOVAIS, 2013, p. 213), o Estado Democrático de Direito contém deveres jurídicos enquanto elementos constitutivos de sua materialidade. ${ }^{2}$

Quando considerados como obrigações conexas a direitos fundamentais dos indivíduos ou da coletividade, isto é, como componentes simétricas (assinalagmáticas) de direitos consagrados em um ordenamento jurídico, os deveres fundamentais podem ser avaliados como decorrências lógicas (a outra face) da limitação do Poder estatal sedimentada nos Estados de Direito (SARLET, 2009, p. 228; NOVAIS, 2010, p. 86-95).

Por outra perspectiva, se considerados como categorias jurídicas autônomas, ou seja, independentes da positivação de direitos, alguns deveres jurídicos podem ser conceitualmente classificados como inerentes ao Estado Democrático de Direito (NABAIS, 1998, p. 35-40; NABAIS, 2007, p. 165-168; LOMBARDI, 1967, p. 1-43), como, por exemplo, o dever de submissão do processo legislativo estatal a procedimentos democráticos, o dever estatal de garantia e proteção aos direitos fundamentais, o dever dos agentes públicos de se submeterem às diretrizes da legalidade ou o dever fundamental dos indivíduos de pagar impostos.

Sem aprofundar na problemática meta-teórica acerca de qual é a melhor concepção institucional-normativa para limitar o poder e regulamentar as relações entre indivíduos e Estado, seja pela positivação de direitos fundamentais seja pela consagração de deveres fundamentais (DUARTE, 2000, p. 413-421; CANOTILHO, 2003, p. 531-532), cumpre determinar qual é a natureza jurídica e qual o significado dos deveres de publicidade e de transparência para as atividades estatais no paradigma do Estado Democrático de Direito.

\subsection{Os deveres de publicidade e transparência enquanto preceitos políticos}

Os deveres de publicidade e de transparência das atividades estatais podem ser compreendidos tanto por uma perspectiva política quanto por uma perspectiva jurídica, e, portanto, pode ser-lhes reconhecida uma natureza jurídica de preceito político, ou, alternativamente, de norma jurídica propriamente dita.

Na perspectiva política, menos do que mandamentos coercitivos de observância compulsória, os deveres de publicidade e de transparência das atividades estatais podem ser vislumbrados como orientações valorativas para adequação das atividades do Estado a um modelo ideal de república democrática. Nessa acepção, os deveres de publicidade e de transparência emergem como preceitos políticos que independem de positivação normativa para possuírem validade.

\footnotetext{
2 A questão com a qual se inicia esta seção é tangenciada no debate jus-filosófico que aborda a controvérsia a respeito de qual é a figura central do Direito Público: o Estado ou a pessoa humana (OTERO, 2009, p. 27-32). Na hipótese de o Estado ser compreendido como o elemento capital do Direito Público é natural que a categoria dos deveres surja como uma figura jurídica proeminente das ordens jurídicas instauradas. Por sua vez, quando a pessoa humana é compreendida como elemento central dos ordenamentos jurídicos, a fórmula de positivação de direitos fundamentais é adotada com primazia nas relações entre indivíduo e Estado.
} 
Noutra via, na perspectiva jurídica, os deveres de publicidade e transparência podem ser compreendidos como normas em favor da exposição dos atos praticados pelos poderes públicos, e, para terem plena eficácia, dependem de sua positivação nos ordenamentos jurídicos.

Conceituando-se, em linhas gerais, o dever de publicidade dos atos estatais, ele pode ser definido como uma diretriz direcionada aos poderes constituídos para que exponham para toda a coletividade os atos e informações de natureza pública. A fim de concretizá-lo, não basta em um Estado Democrático de Direito que os órgãos públicos atendam tão somente a demandas particularmente formuladas, mas é necessário que assumam de maneira abrangente a obrigação de fornecê-las proativa e voluntariamente (MENDEL, 2009, p. 34).

Destarte, o dever de publicidade pode ser definido, sucintamente, como o mandamento obrigacional dirigido ao Estado para que exponha aos seus indivíduos os atos e procedimentos de natureza pública, com exceção daqueles sobre os quais existam, extravagantemente, motivos relevantes para justificar eventual tratamento de sigilo ou de limitada publicização.

Por sua vez, o dever de transparência pode ser qualificado como o mandamento deontológico que reivindica não somente publicidade a determinados atos, fatos ou procedimentos, mas que também demanda que eles sejam exteriorizados de maneira a cumprir com máxima eficiência a sua finalidade (MOTTA, 2010, p. 277). Isto é, de acordo com o dever de transparência, a informação publicizada pelo Estado deve ser efetivamente capaz de informar os seus destinatários em perspectiva substancial e, não apenas, formal (ELIAS, 2012, p. 35).

Nesse sentido, para cumprir o dever de transparência não basta ao Estado publicar informações por intermédio de meios insuficientes para gerar a apreensão do conteúdo difundido. Em consonância com o atual estágio de desenvolvimento das ferramentas de comunicação, é de se esperar que o dever de transparência seja concretizado por meio de esforços condizentes com as possibilidades reais do Estado para disponibilizar informações de maneira eficiente (BARCELLOS, 2008, p. 95).

\subsection{0 nascimento político dos deveres de publicidade e de transparência para as atividades estatais após as revoluções modernas}

A derrocada dos regimes de governo absolutistas na Europa ocidental, nos séculos XVIII e XIX, historicamente, representa um momento paradigmático de rompimento com a velha ordem política do Antigo Regime.

Sob a influência de correntes filosóficas contratualistas, individualistas, iluministas e de relevantes movimentos sociais e econômicos (MIRANDA, 2011, p. 91-92), inaugurou-se a partir das revoluções modernas uma nova ordem política fundamentada no Poder soberano do povo que, em termos contemporâneos, veio a caracterizar os fundamentos do que se concebe como Estado de Direito (NOVAIS, 2013, p. 29-30). 
O Estado de Direito, em sua origem liberal, está diretamente associado à finalidade perseguida pelos revolucionários de limitar a autoridade dos governantes, o que se impôs mediante a consagração da técnica da separação dos poderes e da declaração de direitos individuais (BONAVIDES, 2011, p. 36-37).

O renascimento do ideário republicano propugnado nas revoluções modernas alterou de forma profunda as relações de domínio entre governantes e governados, até então vigorantes, e permitiu a consolidação de um novo modelo de Estado baseado nos princípios democráticos e no primado da soberania da lei (DALLARI, 2007, p. 145-151).

Com o surgimento do Estado de Direito em contraposição ao antigo Estado Absoluto, o poder deixou de estar alicerçado na figura unipessoal dos soberanos e de ser legitimado por argumentos de autoridade baseados no direito divino de reis (BODIN, 1999; BOSSUET, 1999) para estar fundamentado no princípio da soberania popular.

A transposição do fundamento do poder de uma justificativa divina para uma justificativa racional, baseada no postulado político-democrático da soberania popular, pode ser concebida como a gênese ideológica do renascimento dos deveres estatais de publicidade e de transparência para o exercício das atividades públicas nos Estados nacionais modernos em consonância com os preceitos republicanos formulados na Antiguidade.

Embora, em termos jurídicos, seja plenamente defensável conjecturar que o rompimento com a ordem monárquica não tenha automaticamente criado um dever regulamentado de atuação estatal pública e transparente, em termos políticos, é absolutamente sustentável elucubrar que a transição da fundamentação ideológica do poder tenha significado o renascimento dos deveres de transparência e de publicidade para as atividades estatais em consonância com os ideais defendidos pelos revolucionários.

Isso implica dizer que, paralelamente ao rompimento com a ordem autoritária, a instituição de modelos de Estados democráticos e republicanos deu legitimidade a uma pretensão popular de querer ser informada sobre os assuntos públicos relativos às deliberações realizadas pelos detentores do poder e, com isso, fez renascer (ainda que sem coatividade) a obrigação das funções estatais delegadas serem exercidas com préstimo aos deveres de publicidade e transparência. ${ }^{3}$

A partir dos primeiros desenvolvimentos políticos feitos pelos povos antigos até as reformulações modernas e contemporâneas efetuadas em busca do modelo ideal de Estado, persevera a convicção de que os deveres de publicidade e de transparência dos atos estatais estão indissociavelmente ligados à realização dos preceitos democráticos e republicanos (TAVEIRA NETO, 2009, p. 191). Com efeito, desde as primeiras elucubrações feitas pelos povos gregos, aprimoradas pelos

\footnotetext{
Não se ignora que no alvorecer dos Estados de Direito instituídos após as revoluções modernas, a democracia não se instaurou em sua plenitude na vida política e diuturna das sociedades envolvidas. Como se sabe, os ideários revolucionários possuíam limitações ínsitas aos seus próprios objetivos burgueses, e muitos postulados relativos à igualdade, liberdade e fraternidade propugnados pelos revolucionários não se concretizaram de forma ideal (DAHL, 2001, p. 33).
} 
romanos, o conceito de República envolve o dever de que os atos relacionados à coisa pública sejam publicizados (LIMBERGER, 2006, p. 67-68).

O rompimento com a ordem monárquica na Europa ocidental, mais do que uma mudança de sistema político e de forma de governo, representou o renascimento e a transição de um pensamento de legitimação do poder. Com essa mudança de eixo na legitimação da autoridade, o ideário democrático renasceu e, com ele, o pressuposto de que os assuntos da coletividade devem ser tratados em foro público, e não de forma velada.

Nesse novo paradigma, os indivíduos deixaram de ser súditos para tornarem-se cidadãos, e, assim, copartícipes das decisões políticas fundamentais do Estado. Em termos políticos, os deveres de publicidade e de transparência para a atuação dos poderes constituídos reaparecem na Contemporaneidade, não como assunto para deliberação dos novos titulares do poder, mas, sim, como fundamento ínsito à própria ordem política, revolucionariamente instituída.

É o que se depreende do pensamento de Bobbio (1997, p. 83-84) quando assinala que "Um dos lugares-comuns de todos os velhos e novos discursos sobre a democracia consiste em afirmar que ela é o governo do "poder visível'" ou "o governo do poder público em público", e que permite asseverar que democracia e publicidade são conceitos correlacionados.

A importância para o Estado de Direito da exposição de ações com conteúdo juspublicista está contida também no pensamento de Kant (2008, p. 46), quando afirma que toda pretensão jurídica deve ter a possibilidade de se tornar pública, e, na sua concepção: "São injustas todas as acções que se referem ao direito de outros homens, cujas máximas não [se] harmonizem com a publicidade."

Para que o vínculo de delegação do poder em Estados Democráticos representativos e republicanos mantenha-se consentâneo com os fundamentos políticos que o legitimam é essencial que as funções de poder, em sua tridimensionalidade, desenvolvam-se com publicidade e transparência. ${ }^{4}$

A exposição das atividades praticadas por aqueles a quem o poder foi delegado para os seus delegadores consiste em pressuposto ontológico do próprio ideário democrático-republicano, já que sem transparência o poder público ganha caráter privatístico e, assim, perde a sua essência e legitimidade popular. ${ }^{5}$

\footnotetext{
4 Ao se estabelecer um Estado de Direito com regras públicas aplicáveis indistintamente a todos os indivíduos, as decisões de Estado (legislativas, executivas e jurisdicionais) deixam de se tratar de questões privatísticas dos monarcas para se tornarem questões públicas do interesse popular (RIBEIRO, 2012, p. 154-155). Ora, como muito bem coloca a doutrina, os regimes democráticos representativos consolidados a partir das revoluções modernas fundamentam-se no voto direto do povo, que elege republicanamente seus representantes (VENÂNCIO FILHO, 1985, p. 443-444). De modo satisfatório, o processo de escolha de dirigentes depende em parte da difusão de informações acerca da atuação dos indivíduos porventura eleitos e daqueles que pretendem se eleger. Diante da impossibilidade empírica de que o governo do povo seja exercido de forma direta por todos os cidadãos pertencentes à coletividade, as democracias representativas organizam-se como sistemas políticos nos quais o poder é delegado aos mandatários por meio do sufrágio, e, com essa delegação, as decisões políticas essenciais da sociedade são transferidas para o escrutínio da classe política, a quem cabe corresponder aos anseios dos titulares do poder delegado (BONAVIDES, 2010, p. 296).

5 No plano formal, após as revoluções modernas, o dever de publicidade dos atos estatais consolidou-se juntamente com o próprio processo de ressurgimento das codificações. Ao assumir a condição de veículo de expressão da vontade geral, as leis fizeram-se acompanhar da necessidade de tornarem-se conhecidas por todos os seus destinatários (ELIAS, 2012, p. 27). Hodiernamente, tendo em conta a complexidade das sociedades, a mera publicação de leis não é suficiente para garantir o conteúdo do direito, o mesmo se poder dizer sobre os provimentos jurisdicionais e executivos (Cfr. Soares (2004, p. 251)).
} 
Embora usualmente os membros do Poder Judiciário não sejam eleitos, ao contrário do que ocorre com os integrantes dos poderes Legislativo e Executivo, a função jurisdicional tem a mesma fonte de legitimidade das outras funções de Estado. Ainda que seu exercício não caracterize a manifestação indireta da vontade popular, em termos de representação política, como relembra Taruffo (1998, p. 41), ela é resultado do poder indiretamente transmitido pelo povo quando consolidou a concepção tripartida dos poderes.

\section{Os deveres de publicidade e de transparência na jurisdição constitucional}

Hodiernamente, a transparência tem se consolidado como valor fundamental dos Estados Democráticos de Direito ocidentais, como corrobora, entre outras evidências, a propagação de legislações (nacionais e internacionais) que ampliam e positivam o direito subjetivo de acesso a informações públicas.

A sociedade da informação, compreendida atualmente como o fenômeno em que "os valores imateriais - dados, informação, conhecimento científico e tecnológico - passam a constituir a força motriz da formação e desenvolvimento sociais" (GONÇALVES, 2003, p. 28), caracteriza-se pela hipervalorização da informação enquanto recurso fundamental para o desenvolvimento da política, das ciências e da economia (MASUDA, 1986).

Apesar de existir atualmente um considerável consenso na cultura ocidental a respeito da importância de se implementarem institutos e práticas capazes de dar transparência aos atos jurisdicionais sob os quais residam relevantes interesses públicos, certa parcela da doutrina tem criticado o que denomina de transparência generalizada, consistente, basicamente, na inadvertida utilização da transparência enquanto fim em si mesma, e não propriamente em um meio para consecução do interesse público no âmbito do Poder Judiciário.

\subsection{Os deveres jurídicos de publicidade e de transparência para os poderes constituídos no Estado Democrático de Direito}

Conquanto em uma perspectiva política seja possível afirmar que os deveres de publicidade e de transparência tenham surgido na Pós-modernidade de maneira intrínseca à ascensão dos ideais revolucionários (NETO, 2012, p. 491) e que, passados dois séculos desde o renascimento dos ideais democrático-republicanos, esses deveres tenham se consolidado com consistência ideológica ainda mais arraigada, inquestionavelmente, eles não foram instituídos com coatividade universal e automática nos Estados após as revoluções modernas.

Conforme as experiências empíricas do direito e da vida política comprovam, as particularidades endógenas de cada povo, por serem multifacetadas e diversas, geram instituições políticas e 
normativas distintas, que, inevitavelmente, conduzem as sociedades a diferentes modelos de organização do poder.

Com efeito, mesmo que os ideais das revoluções modernas de instituição de governos democráticos e republicanos apontem para a necessidade política de que as atividades do Estado sejam públicas e transparentes, a concretização desses deveres, assim como qualquer outro valor político, depende da atuação de forças sociais que lhes regulamentem e lhes transformem em normas jurídicas de direito positivo.

A poderosa constatação de que todo poder emana do povo é suficiente para justificar a imposição de deveres coativos para que todas as funções do Estado se desenvolvam com publicidade e transparência, de tal sorte que, inquestionavelmente, possam esses deveres ser considerados axiomas (ÁVILA, 1999, p. 163) do Estado Democrático de Direito?

Embora, a priori, seja razoável advogar-se em favor da necessidade de que as atividades estatais sejam coativamente públicas nesse paradigma de Estado, outras necessidades e valores desse próprio paradigma recomendam que, em situações excepcionais, regimes de sigilo sejam adotados para que a soberania estatal, o interesse público ou determinados direitos individuais sejam preservados.

É o que acontece, por exemplo, no âmbito dos poderes Executivo e Legislativo em relação aos segredos de Estado (CASTRO, 2014, p. 80), ou no âmbito do Poder Judiciário em relação aos segredos de Justiça (PIMENTA, 1989, p. 236), nos quais, em razão das características de certas informações, determina-se a não difusão do seu conteúdo para que outros bens e pretensões juridicamente relevantes sejam salvaguardados. ${ }^{6}$

O que se percebe é que, na perspectiva política, não obstante a publicização dos atos e informações de Estado esteja umbilicalmente relacionada à própria definição de regimes de governo como democráticos e republicanos, no plano jurídico, não é razoável se defender que todos os atos e informações estatais devem ser amplamente difundidos em qualquer situação.

Malgrado exista um preceito político de orientação para esses regimes no sentido de que os atos estatais devem ser publicizados em obediência ao primado da soberania popular, a depender da natureza da atividade estatal e dos bens que ela visa proteger, haverá para os legisladores e juízes um espaço de ponderação para definirem sobre o cabimento ou não cabimento da exposição de informações ou atos atinentes ao desempenho de funções estatais (BRANCO; MENDES, 2012, p. 455).

Daí a razão de não ser possível concluir que os deveres de publicidade e transparência sejam axiomas do Estado Democrático de Direito extensíveis para todas e quaisquer atividades desempenha-

\footnotetext{
6 A título exemplificativo, a ampla difusão de informações militares de um determinado Estado pode prejudicar os seus interesses geopolíticos na ordem internacional, ou, a divulgação de informações relativas a fragilidades dos sistemas internos de segurança pública pode prejudicar a própria proteção dos nacionais de um Estado. Em sentido semelhante, a exposição de informações judiciais de natureza penal pode prejudicar investigações criminais em curso ou submeter acusados à difamação ou linchamento público, práticas não consentâneas com garantias também usualmente asseguradas em Estado Democrático de Direito.
} 
das pelos poderes constituídos, não obstante tenha a expansão internacional de legislações em favor do direito à informação sobrelevado a necessidade de - sempre que possível - concretizar-se a transparência e publicidade como forma de se garantir o direito à informação (MENDEL, 2009, p. 34).

De todo modo, considerando-se as particularidades e distintas naturezas das funções legislativas, executivas e jurisdicionais, considera-se que nos procedimentos decisórios de fiscalização constitucional de atos normativos realizados pelas cortes constitucionais, o dever de publicidade com transparência de suas sessões trata-se verdadeiramente de um dever constitucional de caráter organizatório (NABAIS, 2007, p. 265) dos Estados Democráticos de Direito contemporâneos.

Com observância aos efeitos gerais e abstratos ou até mesmo normativos que podem advir dessas decisões se acredita que a ampla concretização do dever de publicidade nos litígios de fiscalização de constitucionalidade indica verdadeira aproximação ou distanciamento do modelo organizativo estatal com os preceitos político-jurídicos do Estado Democrático de Direito, já que não é justificável se restringir o acesso à diafaneidade desses procedimentos.

Como se sabe, as decisões exaradas pelo Supremo Tribunal Federal, tanto em fiscalização abstrata quanto em fiscalização concreta de constitucionalidade, podem adquirir efeitos vinculantes para todos os órgãos do Poder Judiciário e da Administração Pública, o que também ocorre de maneira similar em outras cortes constitucionais ao longo do globo terrestre.

Em controle abstrato de constitucionalidade, no Brasil, é o que se afere literalmente com a dicção do $\mathbb{S} 2^{\circ}$ do art. 102 da Constituição Federal, ao prever que as decisões definitivas de mérito proferidas nas ações diretas de inconstitucionalidade e de declaração de constitucionalidade "produzirão eficácia contra todos e efeito vinculante, relativamente aos demais órgãos do Poder Judiciário e à administração pública direta e indireta, nas esferas federal, estadual e municipal." (BRASIL, 1988).

Ademais, nos procedimentos de Arguição de Descumprimento de Preceito Fundamental é o que se extrai da redação do $\mathbb{S} 3^{\circ}$ do art. 10 da Lei n. 9.882 (BRASIL, 1999), que prevê, de igual modo, eficácia contra todos e efeito vinculante para os acórdãos proferidos pela Suprema Corte nesses processos.

Nas decisões proferidas em Ação Direta de Inconstitucionalidade por Omissão, uma vez reconhecida a inconstitucionalidade e a mora do Legislativo para concretizar o dever de legislar, a jurisprudência brasileira (ADI) n. 3.682 admite a possibilidade de a Corte Suprema fixar prazo para que o legislador colmate a lacuna normativa existente. Nas decisões proferidas em Mandado de Injunção, um dos acórdãos mais recentes da Corte (MI) n. 758, admite ainda que o órgão regulamente provisoriamente matérias pendentes de conformação pelo legislador, dando-lhes efeitos tipicamente aditivos/normativos.

Após a EC n. 45/2004, a Constituição brasileira (art. 103-A) passou a conferir ao Supremo Tribunal Federal a capacidade para atribuir efeitos de natureza vinculante às decisões por ele proferidas também em fiscalização concreta de constitucionalidade, com a criação das famigeradas súmulas vinculantes. Uma vez editados esses instrumentos, as hipóteses exegéticas dos demais órgãos do 
Poder Judiciário e da Administração Pública passam a estar atreladas aos entendimentos constitucionais fixados pelo Tribunal Supremo por meio dessas súmulas.

A tendência de abstrativização do controle difuso de constitucionalidade, materializada no sistema jurídico brasileiro com a criação das súmulas vinculantes, tem se consolidado em diversos outros países, de tal forma que considerável doutrina afirma existir, hodiernamente, um movimento constitucional de aproximação entre os modelos difuso-concreto e concentrado-abstrato no que concerne aos efeitos de suas decisões (SOTELO, 1998, p. 374 e ss.; FERNÁNDEZ SEGADO, 2004, p. 143-208; PERGORARO, 2015, p. 57-105).

No Brasil, entre as mais difundidas teorias e institutos que materializam essa tendência, podem ser destacadas a Teoria da Transcendência dos Motivos Determinantes da sentença, a objetivação dos recursos extraordinários com a aplicação do instituto da repercussão geral e a discussão doutrinária e jurisprudencial sobre ocorrência de mutação constitucional responsável por tornar inexigível a atuação senatorial para atribuir efeitos erga omnes às decisões proferidas em fiscalização concreta (BRANCO; MENDES, 2012, p. 1131 e ss.).

No direito comparado, podem ser destacados os mecanismos da stare decidis e binding effect, da ratio decidendi e holding (NOGUEIRA, 2013), bem como as variações legais e doutrinárias para concretizar a abstrativização dos efeitos das decisões proferidas em fiscalização concreta de constitucionalidade conhecidas como Teoria da Generalização (CANOTILHO, 2003, p. 1024-1025) ou de passagem da fiscalização concreta à fiscalização abstrata (MIRANDA, 2007, p. 332-335).

Independentemente se proferidas em fiscalização abstrata ou concreta, o que a realidade de muitos sistemas de jurisdição constitucional nacionais tem evidenciado é que várias decisões proferidas pelas cortes constitucionais em fiscalização de constitucionalidade de atos normativos têm se revestido de características tipicamente normativas, uma vez que, sucintamente:

a) produzem efeitos contra todos, originariamente ou por abstrativização;

b) vinculam a interpretação dos órgãos do Judiciário e da Administração Pública;

c) definem regras concretas de aplicação da Constituição;

d) normatizam situações até então não regulamentadas pelo legislador.?

Sem se adentrar na discussão doutrinária sobre as diferenças ontológicas entre normas jurídicas - atos tipicamente legislativos - e decisões judiciais - atos tipicamente jurisdicionais (KELSEN, 1998, p. 245; BOBBIO, 2001, p. 69 e ss.), é indubitável que as decisões advindas de cortes cons-

\footnotetext{
7 Excepcionalmente quando admitida no ordenamento jurídico a prolação de decisões jurisdicionais com efeitos aditivos (REVORIO, 2001, p. 81 e ss.).
} 
titucionais em fiscalização de constitucionalidade muito têm se assemelhado, para efeitos práticos, às normas legislativas editadas pelos representantes do Poder popular. ${ }^{8}$

Não obstante, embora não pairem grandes questionamentos sobre a necessidade de a atividade legiferante, praticada pelos detentores do mandato popular, ocorrer em espaço público e de maneira transparente, sobre a atividade jurisdicional praticada pelos juízes constitucionais, não se tem um mesmo consenso e exigência na doutrina.

\subsection{A crítica à transparência generalizada no Poder Judiciário}

Como estudo paradigmático de crítica ao excesso de transparência ou à utilização da transparência como suposta "fórmula mágica" para a resolução dos problemas das democracias contemporâneas, destaca-se o trabalho elaborado por Garapon (2000) a respeito do ritual judiciário e dos elementos simbólicos que compõem a atividade jurisdicional das cortes de Justiça.

O estudo jurídico e sociológico formulado pelo jurisconsulto francês desenvolve sistemáticas críticas à cobertura das atividades judiciais realizadas pelos mass media, concentrando-se, especialmente, nas intercorrências negativas que a transmissão de audiências judiciais por intermédio da televisão ocasiona para as sociedades modernas.

De maneira sucinta, na primeira parte de sua obra Bem julgar: ensaio sobre o ritual judiciário", o autor disserta sobre os diversos elementos simbólicos e factuais que compõem o ritual judiciário em sua completude (GARAPON, 2000, p. 25-153), consistentes: no espaço judiciário; no tempo judiciário; na toga judiciária, nos atores judiciários; no gesto judiciário; e no discurso judiciário; para posteriormente desferir sobrepujante crítica à intermediação de imagens e sons levada a cabo pelas mídias audiovisuais na cobertura de audiências.

Primorosamente, o jurista discorre sobre a relação necessária e indissociável entre o ato de julgar e a sua encenação por meio de liturgias, pontuando que a concretização de julgamentos não pode prescindir da prática de atos factuais e se compor apenas de práticas intelectuais ou morais (GARAPON, 2000, p. 19). De modo eloquente, Garapon (2000, p. 71) assevera que o ritual judiciário, mais do que a consumação estética da ideia de justiça, representa a própria figuração do direito enquanto mecanismo de ordenação social, de modo que as instituições judiciais contemporâneas não podem simplesmente descartar a simbólica contida nos seus atos (GARAPON, 2000, p. 42).

O cerne da crítica elaborada por Garapon contra as transmissões de audiências judiciais feitas pelos meios de comunicação de massa tem como objeto a inabilidade e inaptidão desses meios de comunicação para reproduzirem, fidedigna e sensivelmente, todos os elementos emocionais e

\footnotetext{
8 Embora, utilizando-se da terminologia de Kelsen (1998, p. 247), seja possível afirmar que a moldura para determinação do direito seja mais limitada nos atos de execução (como os jurisdicionais) do que nos atos de criação (como os legislativos) na interpretação constitucional existiria significativo espaço hermenêutico para que os juízes constitucionais confiram significados normativos para o Texto Constitucional, e nesse escopo, definam o significado das normas de decisão aplicadas (que poderão adquirir efeitos de generalidade e abstratividade).
} 
simbólicos que marcam e caracterizam o ritual judiciário enquanto lócus de representação dos valores jurídicos e éticos de uma comunidade.

Segundo o jurista, a cobertura midiática de atos e fatos judiciais ocasiona um distanciamento prejudicial dos telespectadores em relação ao que há de simbólico no ritual judiciário, vez que a mediatização desses eventos sociais provoca indesejáveis rupturas e deturpações na percepção do espaço, do tempo e dos atores que compõem o rito judicial.

Considerando que a compreensão do processo judiciário não é única e puramente racional, mas, também, de ordem emocional e estética, Garapon (2000, p. 42-43) aduz que a privação de contato direto dos jurisdicionados com o delimitado espaço do templo da justiça tolhe-lhes, além da experiência idiossincrática de estarem fisicamente presentes no local de realização do Direito (GARAPON, 2000, p. 45), a oportunidade de experimentarem o diferenciado ritmo de desenvolvimento do tempo da justiça que decorreria em velocidade distinta ao que perpassa o tempo quotidiano (GARAPON, 2000, p. 59-70).

Consoante o doutrinador francês, "é duvidoso que o espetáculo da justiça, visto sem a necessária emoção que envolve o espectador directo, tenha a mesma grandeza." (GARAPON, 2000, p. 60). Na sua aguçada crítica, Garapon (2000, p. 276) contesta a capacidade dos veículos de comunicação social de reproduzirem os fatos e acontecimentos jurisdicionais sem que a encenação judiciária seja banalizada e transformada em um espetáculo midiático.

Nessa vertente, o doutrinador afirma que a transparência acaba por desqualificar os atores oficiais do ritual judiciário, já que a opinião pública, as autoridades judiciárias e todos os atores do processo acabam por ser confundidos e mesclados como uma única parte homogênea constituidora de um mesmo discurso jurisdicional (GARAPON, 2000, p. 280).

Para o professor francófono, menos que um valor inconteste e irrenunciável do Estado Democrático de Direito, a transparência generalizada nas audiências judiciais deve ser problematizada como um fator de risco para a democracia, uma vez que o contato direto com a realidade - não intermediado por nenhuma elaboração ou obstruído por nenhum filtro - provoca distorções na apreensão do conteúdo e do sentido das deliberações jurisdicionais (GARAPON, 2000, p. 274-275).

De acordo com o jurista, as transmissões das sessões de julgamento de um órgão judicial são perigosas não apenas em razão das deturpações que provocam na percepção dos jurisdicionados sobre os eventos judiciais, mas também da posição onipresente e unidiscursiva assumida pela mídia (GARAPON, 2000, p. 285), ${ }^{9}$ que se torna, ao mesmo tempo, atriz e encenadora do discurso judicial.

\footnotetext{
9 "O ritual atribui a cada indivíduo um lugar fixo do qual não pode escapar: atribui uma condição ao discurso de cada um. É certo que todos os intervenientes aspiram abertamente a atingir um ponto de vista universalmente aceite, mas nenhum deles pode arrogar-se uma posição de domínio. A exceção é feita apenas ao juiz, cuja sentença é, ainda assim, sujeita a recurso. Esta situação necessariamente parcial num mesmo espaço manifesta a condição, ao mesmo tempo universal e parcial, de todos os pontos de vista expressos no processo. É essa finitude do discurso que é recusada pelos media, que invocam uma espécie de dom de ubiquidade tecnológica."
} 


\section{Conclusão}

Conceituado em linhas genéricas como um dever de publicidade qualificado, o dever de transparência para as atividades estatais abrange o imperativo obrigacional de que o Estado, de acordo com as possibilidades tecnológicas a sua disposição, empregue os meios necessários para informar eficazmente os indivíduos e a coletividade sobre assuntos de inexorável interesse público.

Em consonância com os ideais iluministas que transferiram a legitimidade do poder político nos Estados modernos de origem divina para fundamentação popular e, mais hodiernamente, em conformidade com os princípios da democracia participativa que têm consolidado a regra da transparência substancial para as atividades realizadas pelos poderes estatais, existem nos Estados Democráticos de Direito verdadeiros mandamentos para que essas atividades sejam expostas com clareza pelos detentores do Poder Público.

No que concerne às audiências e sessões de julgamento realizadas pelas cortes constitucionais na fiscalização de constitucionalidade de atos normativos, compreende-se que mais do que simples obrigações deontológicas, existem para as cortes constitucionais verdadeiros deveres elementares para que exponham diafanamente o conteúdo e a forma como as suas decisões são construídas.

Considerando os objetivos estruturantes dos Estados enquanto instituições de organização do poder, exatamente como ocorre nos denominados deveres constitucionais de carácter organizatório, certas obrigações subsistem para as pessoas de Direito Público independentemente do reconhecimento de direitos ou de posições subjetivas dos seus indivíduos.

Nos atos jurisdicionais praticados pelas cortes constitucionais em fiscalização constitucional, a consagração otimizada do princípio da publicidade exsurge implicitamente como um dever constitucional material autônomo do Estado Democrático de Direito, tanto em razão da natureza materialmente constituinte que pode caracterizar essas atividades, como também em decorrência da não sujeição desses atos à revisão direta de outros poderes.

É evidente que, ao compor uma função essencialmente contramajoritária (ainda que considerada estritamente necessária ao paradigma constitucional), não é republicano e nem democrático que os atos jurisdicionais derrogadores de dispositivos normativos sejam proferidos em regimes de sigilo ou de publicidade limitada, sem que relevantes justificativas sejam capazes de fundamentar a imprescindibilidade de se perpetuarem restrições à transparência nesses procedimentos.

Nesse panorama, o modelo de abertura publicística pioneiramente adotado pelo Supremo Tribunal Federal consuma, com mais diafaneidade e transparência, não apenas um dever constitucional de caráter organizatório dos Estados Democráticos de Direito, mas também garante com mais plenitude e efetividade a proteção das facetas indissociáveis do direito à informação, compreendidas internacionalmente como liberdades fundamentais do homem, especificadamente em procedimen- 
tos decisórios nos quais decisões com repercussões jurídicas e/ou políticas coletivas são proferidas por um número limitado de autoridades.

\section{Referências}

ANCEL, Jean-Pierre. Les opinions dissidentes. 2005. Disponível em: <http://www.courdecassation. fr/IMG/File/opinions_dissidentes_jp_ancel.pdf > . Acesso em: 31 ago. 17.

ABDO, Helena. Mídia e processo. São Paulo: Saraiva, 2011.

ÁVILA, Humberto. Repensando o princípio da supremacia do interesse público sobre o particular. Revista Trimestral de Direito Público, v. 24, 1999.

BARCELLOS, Ana Paula. Papéis do direito constitucional no fomento do controle social democrático: algumas propostas sobre o tema da informação. Revista de Direito do Estado: RDE, n. 12, out./ dez. 2008.

BINENBOJM, Gustavo. A TV Justiça deveria parar de transmitir ao vivo as sessões do Supremo Tribunal Federal? Folha de São Paulo, São Paulo, 02 maio 2009. Caderno Tendências/Debates, p. A3.

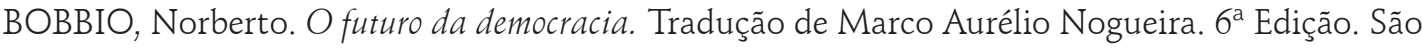
Paulo: Paz e Terra, 1997.

BOBBIO, Norberto. Teoria da norma jurídica. Tradução Fernando Pavan Baptista e Ariani Bueno Sudatti. Bauru: Edipro, 2001.

BODIN, Jehan. Os seis livros da República. In: CHEVALLIER, Jean Jacques (Org.). As grandes obras políticas de Maquiavel a nossos dias. 8. ed. Tradução Lydia Cristina. Rio de Janeiro: Agir, 1999.

BONAVIDES, Paulo. Ciência Política. 17. ed. São Paulo: Malheiros, 2010.

BONAVIDES, Paulo. Curso de Direito Constitucional. 26. ed. São Paulo: Malheiros, 2011.

BOSSUET, Jacques. A política extraída da Sagrada Escritura. In: CHEVALLIER, Jean Jacques (Org.). As grandes obras políticas de Maquiavel a nossos dias. 8. ed. Tradução Lydia Cristina. Rio de Janeiro: Agir, 1999.

BRANCO, Paulo Gustavo; MENDES, Gilmar Ferreira. Curso de Direito Constitucional. 7. ed. São Paulo: Saraiva, 2012.

CANOTILHO, José Joaquim Gomes. Direito Constitucional e Teoria da Constituição. 7. ed. Coimbra: Almedina, 2003.

CAPPELLETTI, Mauro. Il controlo giudiziario di costituzionalità dele leggi nel diritto comparato. Milhano: Giuffrè, 1968.

CASTRO, Raquel Alexandra Brízida. O Estatuto Constitucional dos Media e as Exceções ao Princípio da Publicidade da Actuação dos Poderes Públicos. In: MORAIS, Carlos Blanco de; DUARTE, Maria Luísa; CASTRO, Raquel Alexandra Brízida (Coord.). Media, Direito e Democracia: I curso pós-graduado em direito da comunicação. Coimbra: Almedina, 2014. 
CELOTTO, Alfonso. La Corte costituzionale: quando il diritto giudica la politica. Bologna: il Mulino, 2004.

DAHL, Robert A. Sobre a democracia. Tradução Beatriz Sidou. Brasília: Universidade de Brasília, 2001.

DALLARI, Dalmo de Abreu. Elementos de teoria geral do estado. 26. ed. São Paulo: Saraiva, 2007.

DUARTE, David. A norma de universalidade de direitos e deveres fundamentais: esboço de uma anotação. Boletim da Faculdade de Direito, Coimbra, v. 76, 2000.

EDWARD, David. How the Court of Justice works. European Law Review, i. 20, p. 555-558, 1995.

ELIAS, Gustavo Terra. Da publicidade à transparência: o percurso para a reafirmação da democracia participativa. Fórum administrativo, v. 12, n. 141, nov. 2012.

FAVOREU, Louis. Les cours constitutionnelles. Paris: Puf, 1992.

FERNÁNDEZ RODRIGUEZ, José Julio. La justicia constitucional europea ante el siglo XXI. Madrid: Tecnos, 2002.

FERNÁNDEZ SEGADO, Francisco. La Justicia constitucional ante el siglo XXI: la progresiva convergencia de los sistemas americano y europeo-kelseniano. Revista Latino-Americana de Estudos Constitucionais, n. 4, jul./dez. 2004.

FERNÁNDEZ SEGADO, Fernando, La recepción del Sondervotum en Alemania. In: Revista Iberoamericana de Derecho Procesal Constitucional, n. 12, 2009.

FONTE, Felipe de Melo. Jurisdição constitucional e participação popular: o STF na era da TV Justiça. Rio de Janeiro: Lumen Juris, 2016.

FROMONT, Michel. La justice constitutionelle dans le monde. Paris: Dalloz, 1996.

GARAPON, Antoine. Bem julgar: ensaio sobre o ritual judiciário. Tradução Pedro Filipe Henriques. Bobadela: Instituto Piaget, 2000.

GARCÍA BELAUNDE, Domingo; FERNÁNDEZ SEGADO, Francisco (Coord.). La jurisdicción constitucional en Iberoamericana. Madrid: Dykinson, 1997.

GONÇALVES, Maria Eduarda. Direito da informação. Coimbra: Almedina, 2003.

KANT, Immanuel. A paz perpétua. Tradução Artur Morão. Porto Alegre: Lusosofia. 2008.

KELSEN, Teoria Pura do Direito. Tradução João Baptista Machado. 6. ed. São Paulo: Martins Fontes, 1998.

LIMBERGER, Têmis. Transparência administrativa e novas tecnologias: o dever de publicidade, o direito a ser informado e o princípio democrático. Interesse Público, v. 8, n. 39, set./out. 2006.

LOMBARDI, Giorgio M. Contributo allo studio dei doveri costituzionali. Milano: A. Giuffrè, 1967. 
LUTHER, Jorg.; ROMBOLI, Roberto; TARCHI, Rolando (Cura di). Esperienze di giustizia costituzionale. Torino: Giappichelli, 2000.

MASUDA, Yoneji. The information Society. Tóquio: Institute for the Information Society, 1986.

MEDINA, José Miguel Garcia. Juízes do Supremo Tribunal Federal são midiáticos. Conjur, 27 jan. 2014. Disponível em: <http://www.conjur.com.br/2014-jan-27/jose-miguel-medina-juizes-supremo-sao-midiaticos\#_ftn1>. Acesso em: 31 ago. 2017.

MENDEL, Toby. Liberdade de informação: um estudo de direito comparado. 2. ed. Brasília: UNESCO, 2009.

MENDES, Gilmar Ferreira. Jurisdição constitucional: o controle abstrato de normas no Brasil e na Alemanha. 6. ed. São Paulo: Saraiva, 2014.

MIRANDA, Jorge. Manual de Direito Constitucional. 6. ed. Coimbra: Coimbra Editora, 2007. t. II.

MIRANDA, Jorge. Manual de Direito Constitucional. 9. ed. Coimbra: Coimbra Editora, 2011. t. I.

MORAIS, Carlos Blanco de. Justiça Constitucional. Garantia da Constituição e Controlo da Constitucionalidade. 2. ed. Coimbra: Coimbra Editora, 2006. t. I.

MOTTA, Fabrício. Publicidade e transparência nos 10 anos da Lei de Responsabilidade Fiscal. Revista Técnica dos Tribunais de Contas, Belo Horizonte, a. 1, set. 2010.

NABAIS, José Casalta. O dever fundamental de pagar impostos. Coimbra: Almedina, 1998.

NABAIS, José Casalta. Por uma liberdade com responsabilidade: estudos sobre direitos e deveres fundamentais. Coimbra: Coimbra Editora, 2007.

NEUBERGER, David. Open Justice Unbound? Judicial Studies Board Annual Lecture. Judicial Studies Board Annual Lecture, p. 12-13, 2011. Disponível em: <http://netk.net.au/Judges/Neuberger2. pdf>. Acesso em: 31 ago. 2017.

NOGUEIRA, Gustavo Santana. Precedentes vinculantes no direito brasileiro e comparado. 2. ed. Salvador: JusPodivm, 2013.

NOVAIS, Jorge Reis. As Restrições aos Direitos Fundamentais não Expressamente Autorizadas pela Constituição. 2. ed. Coimbra: Coimbra Editora, 2010.

NOVAIS, Jorge Reis. Direitos Fundamentais e Justiça Constitucional em Estado de Direito Democrático. Coimbra: Coimbra Editora, 2012.

NOVAIS, Jorge Reis. Contributo para uma teoria do estado de direito. Coimbra: Almedina, 2013.

NETO, Luisa. Um outro tipo de "Freios e Contrapesos": A Comunicação Social no contexto do Estado de Direito Democrático. In: SOUSA, Marcelo Rebelo de et al. (Coord.). Estudos de Homenagem ao Prof. Doutor Jorge Miranda. Coimbra: Coimbra Editora, 2012.

OTERO, Paulo. Instituições Políticas e Constitucionais. Coimbra: Almedina, 2009. v. I. 
PASQUINO, Pasquale. Disclosed and Undisclosed Votes in Constitutional/Supreme Courts. In: ELSTER, Jon. (Ed.). Secrecy and Publicity in Votes and Debates. Cambridge: Cambridge University Press, 2015.

PERGORARO, Lucio. Lineamenti di giustizia costituzionale comparata. Torino: Giapichelli, 1998.

PERGORARO, Lucio. Giustizia costituzionale comparata: Dai modelli ai sistemi. Torino: G. Giappichelli Editore, 2015.

PERI, Antonina. Judicial Independence Vs. Judicial Accountability. Judicial Selection Model For Constitutional Courts. A Comparative Analysis. In: Comparative Law Review, v. 3, i. 1, 2012.

PIMENTA, José da Costa. Introdução ao Processo Penal. Coimbra: Almedina, 1989.

RAFFAELLI, Rosa. Dissenting opinions in the Supreme Courts of the Member States. Study for the European Parliament. Directorate General for Internal Policies - Policy Department C: Citizens' Rights and Constitutional Affairs, 2012.

REVORIO, Francisco Javier Díaz. El control de la constitucionalidad de las omisiones legislativas relativas en el derecho comparado europeo. Revista Española de Derecho Constitucional, v. 21, n. 61, 2001.

RIBEIRO, Maurício Carlos. In: FREITAS, Daniela Bandeira de; VALLE, Vanice Regina Lírio do (Coord.). Direito Administrativo e democracia econômica. Belo Horizonte: Fórum, 2012.

SARLET, Ingo Wolfgang. A eficácia dos direitos fundamentais: uma teoria geral dos direitos fundamentais na perspectiva constitucional. 9. ed. Porto Alegre: Livraria do Advogado, 2009.

SILVA, Virgílio Afonso da; MENDES, Conrado Hübner. Entre a transparência e o populismo judicial. Folha de São Paulo, 14 maio 2009. Opinião, p. A14. Disponível em: <http://www1.folha.uol.com. br/fsp/opiniao/fz1105200908.htm >. Acesso em: 31 ago. 2017.

SOARES, Fabiana de Menezes. Teoria da legislação: formação e conhecimento da lei na idade tecnológica. Porto Alegre: S.A. Fabris, 2004.

SOTELO, José Luiz Vásquez. A jurisprudência vinculante na common law e na civil law. In: CALMON FILHO, Petronio; BELTRAME, Adriana. (Org.). Temas atuais de direito processual ibero-americano. Rio de Janeiro: Forense, 1998.

TARUFFO, Michele. Il significato costituzionale dell'obligo di motivazione. In: GRINOVER, Ada Pellegrini; DINAMARCO, Cândido Rangel; WATANABE, Kazuo. (Coord.). Participação e processo. São Paulo: Revista dos Tribunais, 1998.

TAVARES, André Ramos. Teoria da justiça constitucional. São Paulo: Saraiva, 2005.

TAVEIRA NETO, Francisco. O princípio constitucional da publicidade na gestão democrática da cidade. Interesse Público, v. 11, n. 56, jul./ago. 2009.

URBANO, Maria Benedita. Curso de Justiça Constitucional: evolução histórica e modelos de controlo da constitucionalidade. Coimbra: Almedina, 2014. 
VENÂNCIO FILHO, Alberto. Democracia e informação. Revista brasileira de estudos politicos, n. 60 61, jan./jul. 1985.

WEST, Sonja R. The Monster in the Courtroom. The Brigham Young University Law Review, n. 6, 2012.

Data de submissão: 15 de junho de 2017 Avaliado em: 03 de julho de 2017 (AVALIADOR B) Avaliado em: 06 de julho de 2017 (AVALIADOR C) Avaliado em: 12 de julho de 2017 (AVALIADOR D) Aceito em: 20 de novembro de 2017 